2018

\title{
How to Prepare Interprofessional Teams in Two Weeks: An Innovative Education Program Nested in Telehealth
}

\author{
Tina S. Haney
}

Old Dominion University

Karen Kott

Old Dominion University

Carolyn M. Rutledge

Old Dominion University

Bruce Britton

Christianne N. Fowler

Old Dominion University

See next page for additional authors

Follow this and additional works at: https://digitalcommons.odu.edu/nursing_fac_pubs

Part of the Nursing Administration Commons, and the Public Health and Community Nursing Commons

\section{Repository Citation}

Haney, Tina S.; Kott, Karen; Rutledge, Carolyn M.; Britton, Bruce; Fowler, Christianne N.; and Poston, Rebecca D., "How to Prepare Interprofessional Teams in Two Weeks: An Innovative Education Program Nested in Telehealth" (2018). Nursing Faculty Publications. 21.

https://digitalcommons.odu.edu/nursing_fac_pubs/21

\section{Original Publication Citation}

Sweeney Haney, T., Kott, K., Rutledge, C. M., Britton, B., Fowler, C. N., \& Poston, R. D. (2018). How to prepare interprofessional teams in two weeks: An innovative education program nested in telehealth. International Journal of Nursing Education Scholarship, 15(1), 1-9. doi:10.1515/ijnes-2017-0040 
Authors

Tina S. Haney, Karen Kott, Carolyn M. Rutledge, Bruce Britton, Christianne N. Fowler, and Rebecca D. Poston 


\title{
How to Prepare Interprofessional Teams in Two Weeks: An Innovative Education Program Nested in Telehealth
}

${ }^{1}$ Old Dominion University, 4608 Hampton Blvd, Norfolk VA 23529, USA, E-mail: thaney@odu.edu

${ }^{2}$ Eastern Virginia Medical School, 825 Fairfax Ave, Norfolk, VA 2507, USA

\begin{abstract}
:
Problem: Preparing health professional students for interprofessional collaborative practice, especially at a distance where provider shortages prevail remains difficult.

Approach: A two-week interprofessional education (IPE) immersion experience preparing students from 11 disciplines and four universities was implemented. Week-one, using online technology, students develop/present an interprofessional careplan for a complex patient. Students then meet face-to-face to conduct group interviews with two standardized patient dyads. Week-two, students develop a website for use of the patient dyads. Websites are presented to faculty and fellow students via an online virtual meeting space.

Outcomes: To date, 594 students have participated demonstrating capacity to: 1.effectively engage in interprofessional care, 2. utilize Telehealth to impact care and break down barriers of isolation, and 3. implement skills to advance healthcare.

Conclusion: IPE combined with Telehealth technology provides future providers with knowledge and skills for interprofessional care regardless of geographic barriers.

Next Step: Integrate more technology using mobile devices and enhance the evaluation process.

Keywords: Telehealth, interprofessional teams, education

DOI: 10.1515/ijnes-2017-0040

Received: June 7, 2017; Revised: January 9, 2018; Accepted: January 9, 2018

Healthcare is in a state of rapid change. High healthcare cost, limited access, and restrictions on scope of practice for some providers burden an already stressed system. As Americans age, many suffer from multiple chronic medical and behavioral conditions that require greater collaboration between healthcare professions to effectively and efficiently care for their complex needs (Healthy People 2020, 2016). Providing this care is further complicated by the fact that the percentage of people living in rural areas ages 65 years plus $(18.6 \%)$ is greater than those living in urban or metropolitan areas (16.3\%) (Rural Health Information Hub, 2017). In addition, rural hospitals are closing at an unprecedented rate (Ellison, 2016); and inner city hospitals have decreased in number by approximately $53 \%$ since 1970 (Rojas-Burke, 2014). This leaves many Americans without access to primary and acute care services. Whether living in urban or rural areas, a lack of access due to the physical environment limits healthcare. Social determinants that impact education and collaboration of healthcare professionals will likely continue to limit the access and effectiveness of care (San Martin-Rodriguez et al., 2005). Telehealth and team based interprofessional education and collaborative practice can provide innovative solutions to these compounding issues.
\end{abstract}

\section{Background}

Organizations such as the Institute of Medicine and the World Health Organization call for restructuring of care and highlight interprofessional collaborative approaches as innovative and necessary components of a high functioning health care system (Institute of Medicine, 2001; World Health Organization, 2010). A Cochrane review completed in 2013 revealed 15 studies that showed the effectiveness of interprofessional interventions in improving diabetes care, patient satisfaction, collaborative care, and reduction in clinical errors in emergency departments (Reeves, Perrier, Goldman, Reeth, \& Zwarentsten, 2013). Yet, much provider education and practice occur in "silos" meaning there is a segregation of professions, ideas, data collection, and viewpoints

Tina Sweeney Haney is the corresponding author.

(c) 2018 Walter de Cruyter CmbH, Berlin/Boston. 
regarding the evaluation and treatment of a patient. Each discipline or profession works within its own distinct environment even when located within the same educational or health care organization. Attempts to integrate various professions by establishing provider teams while in educational environments is a step in the right direction. However; unless purposeful efforts are made to break down barriers between the professions and team members, the silo approach prevails. This may leave care fragmented even when professional students and providers are geographically together.

The current Affordable Care Act of 2010 offers opportunities to create new healthcare models (U.S Government Publishing Office (GPO), 2010). Specific models may include access to multiple professions, collaborations between the profession as well as telehealth with the goal of addressing issues of access and the provision of quality healthcare to address the healthcare crisis. At the core of successful interprofessional practice are teams united with shared values that place the patient at the center of their care. High functioning interprofessional teams "leverage information, experience, technology, and a culture of teamwork thus providing value for patients and families" (Nester, 2016, p. 129). Institutions of higher learning are challenged to develop health care professionals with competency in interprofessional collaborative practice and are mandated by their accrediting bodies to demonstrate how they have incorporated the principles of Interprofessional Education (IPE) in their curricula (Zorek \& Raehl, 2013). Institutional membership in the Interprofessional Education Collaborative (IPEC) has grown from six founding organizations in 2009 to 20 in 2017, demonstrating commitment from the leaders of many health care professions (Interprofessional Education Collaborative, 2016). The Core Competencies for Interprofessional Collaborative Practice (Interprofessional Education Collaborative Expert Panel, 2016) informs the development of content and skills in health care provider curricula.

As health care systems seek to increase access to care, improve efficiencies of care, and increase interprofessional collaboration for rural and medically underserved populations, innovations in telehealth have become integral parts of the health care delivery model. Telehealth is a necessary tool to bind interprofessional teams together across diverse economical and geographical landscapes in healthcare and is a necessary component of interprofessional education approaches. High utilization of telehealth technologies requires providers with adequate training and demonstrated competencies in the technologically mediated delivery of care. Thus, educators responsible for the training of the next generation of safe, efficient, competent health care providers must engage in their own disruptive innovative approaches to education that include telehealth as a focus in their curricula.

Nursing has led the call for recognition of telecommunication technology to collaborate starting with the use of the telephone. In 1997, the National Council of State Boards of Nursing (NCSBN) released a position paper recognizing the use of telecommunication as a provision of nursing services. This position paper, updated in 2014, expands telehealth nursing practice beyond the telephone, reinforcing the concept that services through internet or other electronic channels is practice (National Council of State Board of Nursing, 2014). Additionally, in 1997, the American Academy of Ambulatory Care Nursing realized the impact of telecommunication technology on patient care within practices and developed the Scope and Standards of Telehealth Practice for Professional Nursing (American Academy of Ambulatory Care Nursing, 2011) now in its 5th edition. While telehealth has not been mandated as curriculum content for all health professionals, the American Medical Association has a new policy that encourages medical education programs to include training and demonstration of core competency development in telemedicine (American Medical Association, 2016). Additionally, there are policies, position papers, and practice guidelines available from the American Physical Therapy Association, American Occupational Therapy Association, and the American Speech-Language-Hearing Association regarding the impact of telehealth technology on the delivery of care (American Physical Therapy Association, 2017). Telehealth is one of the few "team sports" in healthcare and by its very nature facilitates a collaborative practice model to support highly efficient and effective coordinated care (Ferris, 2006).

\section{Theoretical basis for interprofessional educational experience}

Experiential learning or theory of learning set forth by Kolb (2014) is used as the theoretical framework for this program. According to the Kolb's Theory of Learning (2104), individuals learn through concrete experience (feeling), reflective observation (watching), abstract-conceptualization (thinking), or active experimentation (doing). Kolb's Learning Theory has been used as a framework to develop and evaluate numerous educational programs. For instance, Poore, Cullen, Schaar, (Poore, Cullen, \& Schaar, 2014) utilized the framework to develop a simulation program in nursing. In the rotation presented in this paper, the theory constructs were used as follow: concrete experiences (students developing a plan of care for a patient as an interprofessional team when they are unknown to each other), observation and reflection (group discussion about plans of care, self and peer reviews), abstract conceptualization (drawing conclusion about their actions as an interprofes- 
sional team to prepare for two new patient encounters and development of an interprofessional educational tool), and active experimentation (conducting a visit, planning care, discussing experience and developing a web-based product for education as an interprofessional team).

\section{Methods}

In 2014, a state funded university located in the southeast United States, in collaboration with a private medical school located within the region, received grant funding from the Health Resources and Services Administration (HRSA) to explore innovative approaches to preparing students to work effectively as interprofessional team members and to increase their competency with telehealth delivery models for care. The university's Institutional Review Board approved the study prior to implementation. Initial students included the professions of: family nurse practitioner, clinical nurse specialist, doctor of physical therapy, speech language pathology, clinical counseling, and $4^{\text {th }}$ year medical students. To date 594 students from eleven different professions (with the addition of athletic training, dental hygiene, social work, pediatric nurse practitioner, and pharmacy students) and four universities have participated in the experience.

The same rotation is offered nine times per year through the Fall, Spring and Summer semesters. This allows all students to participate when they have room in their schedules, addressing the challenge that often plagues interprofessional education planning of already overcrowded programs of study and disparate training schedules. Most students either take this rotation as a stand-alone one credit course or as an assignment within one of their program specific courses. Per each faculty instructor, students from the varying programs are graded as appropriate such as Pass/Fail or given a letter grade.

The purpose of the rotation is twofold: (1) prepare participants for interprofessional collaborative practice based on the Interprofessional Education Competencies (American Physical Therapy Association, 2017) and (2) introduce students to telehealth. This paper will outline the development of the 2-week interprofessional immersion experience enhanced with a telehealth focus. The processes are outlined in Table 1.

Table 1: Outline of Two-week Telehealth Enhanced IPE Program.

\begin{tabular}{|c|c|c|}
\hline Length & Assignments & Expectations \\
\hline$\frac{\text { Phase 1: }}{1 \text { week }}$ & Review and complete 5 online modules & $\begin{array}{l}\text { The development of the care plan is discussed by each team } \\
\text { in-person during the in-person Seminar day (Phase 2) }\end{array}$ \\
\hline On-line & $\begin{array}{l}\text { Develop an interprofessional care plan } \\
\text { for a patient with Multiple Complex } \\
\text { Medical Conditions }\end{array}$ & \\
\hline$\frac{\text { Phase 2: }}{1 \text { day }}$ & $\begin{array}{l}\text { Participate in Standardized Patient } \\
\text { (SP) experience as an Interprofessional } \\
\text { Team }\end{array}$ & $\begin{array}{l}\text { Participate in workshop with interprofessional team using } \\
\text { motivational interviewing through face to face and telehealth } \\
\text { encounters with SPs during in-person seminar day }\end{array}$ \\
\hline In-Person & $\begin{array}{l}\text { Face-to-Face } \\
\text { Telehealth Visit } \\
\text { Telehealth Equipment }\end{array}$ & $\begin{array}{l}\text { Receive hands-on training in the use of various telehealth } \\
\text { modalities (Store \& Forward, Live, etc.) }\end{array}$ \\
\hline $\begin{array}{l}\text { Phase 3: } \\
\text { 1 week } \\
\text { On-line }\end{array}$ & $\begin{array}{l}\text { Develop a website or APP to support } \\
\text { patients and their families }\end{array}$ & $\begin{array}{l}\text { Students work together using distance technology (WebEx) } \\
\text { as a team to develop either a website or mobile APP for use } \\
\text { by patients and their families based on SP case }\end{array}$ \\
\hline 1 hour & Present Website or APP & $\begin{array}{l}\text { Group presents Website or APP via distance technology } \\
\text { (WebEx) to other participants and faculty for discussion }\end{array}$ \\
\hline On-line & & $\begin{array}{l}\text { Feedback on student experience and final reflective writing } \\
\text { assignment collected at conclusion }\end{array}$ \\
\hline
\end{tabular}

\section{Phase 1: asynchronous online learning (1 week)}

Phase one consists of students reviewing five learning modules and developing a group care plan using an asynchronous online learning platform. The self-paced learning modules have been developed by interprofessional faculty team members and take approximately 30 to 60 minutes to complete. Module details are outlined in Table 2. 
Table 2: Phase 1: Inter-professional Online Learning Modules and Activity.

\begin{tabular}{lll}
\hline Topics & Activities & Delivery Model \\
\hline Learning & Complete 5 narrated modules on: & $\begin{array}{l}\text { Online narrated Learning } \\
\text { Module embedded in } \\
\text { Blackboard }\end{array}$ \\
& Multiple Chronic Conditions & \\
Modules & Healthcare Finance & Assigned readings \\
& Interprofessional Practice and Collaboration & \\
Ethics of Interprofessional Practice & \\
Telehealth & Develop Plan of Care for patient with Multiple Complex & Online discussion forum \\
& Chronic Conditions presented as a written scenario & \\
& Patient with history of recent Cerebral Vascular Accident & \\
& (CVA) and multiple chronic conditions & \\
\hline
\end{tabular}

The modules utilize narrated PowerPoints, videos, web links, assigned readings, and interactive activities. At the completion of the modules, interprofessional student groups of five to six students work on a plan of care for a patient living in a rural area with recent discharge to home following a stroke. The students' challenges are to: (1) collaboratively create a plan of care that is patient-centered, has a common goal, shared responsibilities, and includes everyone's voice in the plan, (2) incorporate telehealth technologies into the plan, and (3) utilize virtual meeting spaces in an online environment (i. e. discussion forums, Google Hangout, WebEx ${ }^{\mathrm{TM}}$ ). These challenges are designed to help the students appreciate the uses of telehealth and develop expertise in working interprofessionally at a distance using technology to address healthcare needs of those with limited access to varying professions.

\section{Phase 2: simulated interprofessional and telehealth experience (1 day)}

On the Monday following the beginning of Phase One, students convene at a Standardized Patient Simulation center. Details from this experience are noted in Table 3.

Table 3: Face to Face Immersion Experience of Interprofessional Teams with Standardized Patient.

\begin{tabular}{llll}
\cline { 2 - 3 } & Topic & Activities & Delivery Model \\
\cline { 2 - 4 } & Group Presentation & Interprofessional teams present their plan of care & Live classroom \\
presentation
\end{tabular}

Presentation of Care Plan. Following introductions and an overview of the day, student groups share their plan of care developed during their virtual discussions. The student groups are challenged to identify the best care plan. The best care plans clearly delineate the "patient at the center" rather than focusing on the roles of each provider. Each student is able to identify a role when the focus is on the patient's identified needs and desires, but compromise care when the focus is too much on specific professional roles.

Standardized Patient Encounter. Student groups then conduct "visits" with two Standardized Patient dyads (patient and family member) utilizing both face-to-face and a real- time telehealth platform. Standardized patients portray realistic patient experiences demonstrating the complexities of caring for patients with multiple chronic conditions in locations such as rural and medically underserved areas. Each standardized patient dyad is designed by the interprofessional faculty to have needs that require input from the varying professionals. The students first conduct a group face-to-face visit as an interprofessional team and then a visit via telehealth. The groups of students must determine the patient's current status, develop a plan of care incorporating the patient's needs and wants, and utilizing the expertise of each team member.

Case One involves a 17 and 8-month old female with a recent diagnosis of osteogenic sarcoma. She is completing 3-months of chemotherapy and preparing for limb salvage surgery. She presents with complaints of mouth 
sores, food intolerance, chronic pain, difficulty ambulating, malaise, worsening grades, and depression. Half of the students see this dyad through the face-to-face group visit. The other half of the students see the dyad from their home via telehealth because the home health agency raised concerns about going to this neighborhood due to safety.

Case Two involves an elderly Vietnam War veteran exposed to Agent Orange. He is a known alcoholic with a long history of uncontrolled diabetes and is status post below the knee amputation. He has a history of nonadherence with self-care and is experiencing a poor healing wound to his limb and difficulty swallowing. He resides in a rural setting with transportation challenges due to distance and ambulation difficulties. He is being seen with his estranged wife by half of the students via telehealth as a follow-up to his wound care visit at the Emergency Department. The students that saw the pediatric patient face-to-face conduct a visit with the veteran via telehealth. This allows the students to see at least one patient dyad via telehealth and one through a face-to-face visit.

Each interprofessional group's telehealth visit is facilitated by a member of the interprofessional faculty following the same structure. Students are first provided a brief overview of the telehealth video equipment and goals for the 30-minute visit. Table 4 outlines the telehealth encounter format. After a brief break, the students move to the second standardized patient case with the goal of perfecting their performance in interprofessional collaboration and use of telehealth.

Table 4: Telehealth/Standardized Patient Encounter Format.

\begin{tabular}{|c|c|c|}
\hline Time & Activity & Purpose \\
\hline 15 Minutes & $\begin{array}{l}\text { Students review a brief written outline of the } \\
\text { case }\end{array}$ & To plan the patient interaction \\
\hline 15 Minutes & $\begin{array}{l}\text { All students in the group interview the } \\
\text { patient and caregiver }\end{array}$ & $\begin{array}{l}\text { Determine the patients' and caregiver's } \\
\text { needs, work interprofessionally, use the } \\
\text { telehealth technology }\end{array}$ \\
\hline 15 Minutes & $\begin{array}{l}\text { The interview stops and the students review } \\
\text { their process through group discussion. }\end{array}$ & $\begin{array}{l}\text { Determine how they are functioning as an } \\
\text { interprofessional team }\end{array}$ \\
\hline 15 Minutes & Students proceed with the interview & Complete interview and outline a plan of care \\
\hline 15 Minutes & $\begin{array}{l}\text { Students receive feedback from faculty and } \\
\text { standardized patients }\end{array}$ & $\begin{array}{l}\text { Highlight competencies in communication } \\
\text { and interprofessional collaborative practice }\end{array}$ \\
\hline
\end{tabular}

Telehealth Encounter. Following the active experimentation with the telehealth visits, the faculty review with the students the unique skills necessary in conducting a telehealth encounter. Telehealth etiquette and the unique human factors necessary for a successful telehealth encounter are highlighted. Specific focus on factors related to telehealth etiquette that interfere with the telehealth encounter including Health Insurance Portability and Accountability Act (HIPAA) violations, lighting, positioning, distracting behaviors, background noises, and colors are addressed (Haney, Kott \& Fowler, 2015). Communication techniques such as nonverbal empathy and deliberate empathy statements necessary for a telehealth visit are reviewed. Students are challenged to consider what went well with their telehealth visits and what they would do differently.

Telehealth Equipment. Following the Standardized Patient encounters, students have the opportunity to practice with various types of telehealth equipment: telemedicine cart, home based Bluetooth equipment, iPhone accessories, and wearable devices. The telemedicine cart is equipped with the following peripherals: otoscope, ophthalmoscope, stethoscope, and high resolution camera. Home based Bluetooth equipment includes peripherals such as scales, oximetry, and blood glucose monitors. Students practice sending patient data via the telemedicine cart in both real time and store and forward modalities. Students see how this type of equipment could be used to remotely monitor patients and serve as additional communication, support, and an educational platform for the patient and caregiver. The students are then exposed to the iPhone as a newer technology that can adapt to a personal handheld device for use with peripherals such as an otoscope, ophthalmoscope, and electrocardiogram. Students program a wearable device that can notify family members and heath care providers of patients' sleep and activity patterns or falls. Finally, students discuss how the telehealth technology could aid in providing the previously visited standardized patient dyads with access to varying professions. They are encouraged to explore the use of interprofessional care facilitated by telehealth.

Communication, Teamwork, and Ethical Dilemmas. As a large group, students discuss factors that can impact the success of the interprofessional team. Specific emphasis is placed on ethical conflict embedded in the standardized patient cases allowing students to discover how to support each other when faced with an ethical dilemma. Faculty debriefing allows for students to identify their own strengths and weaknesses within the context of their interprofessional student group and clarify the principles and values that guide their profes- 
sional and personal ethical decision making. Students also have an opportunity to discuss unique ethical issues related to interprofessional collaborative care and a telehealth visit.

\section{Phase 3: website/app development (1 week)}

In phase three, the student groups develop a website or mobile App to support patients and families similar to either the pediatric or the veteran standardized patients encountered in phase two. Table 5 describes this activity.

Table 5: Phase 3: Website/Mobile App Development.

\begin{tabular}{lll}
\hline Topic & Activities & Delivery Model \\
\hline Website/App Development & Student IP teams developed Website or App & Virtual Meeting \\
& for SP & WebEx \\
& Developed at a distance \\
& Presented to faculty and other students via & \\
& WebEx & \\
\hline
\end{tabular}

Group work during the second week of the rotation occurs through technology using virtual meeting platforms as students are located in different geographic regions across the state. Students are encouraged to use Weebly ${ }^{\odot}$ for the website development and Appy Pie for the development of a mobile application, as they are free to users and set-up for intuitive use by individuals not experienced in website/app development. At the end of week two, the student groups present their website via a virtual meeting platform to another student group and interprofessional faculty members. This project facilticates skill development in effective collaboration at a distance. In addition, students develop greater understanding of the importance and utilization of telehealth modalities.

\section{Outcomes}

The implementation and success, to date, of the IPE/Telehealth program is measured in multiple ways. Faculty input is measured through focus group discussions and participation efforts, and students are assessed using surveys and observation. The number of students vary from 36-40 per rotation with the current participation data included in Table 6.

Table 6: Participants by disciplines.

\begin{tabular}{ll}
\hline Discipline/Degree Programs & Number $\mathbf{5 9 4}$ \\
\hline Athletic Training (MS) & 24 \\
Clinical Counseling (MS) & 41 \\
Clinical Nurse Specialists (CNS) & 24 \\
Family Nurse Practitioners (FNP) & 92 \\
Medicine (MD) & 207 \\
Pediatric Nurse Practitioners (PNP) & 2 \\
Pharmacy (PharmD) & 25 \\
Physical Therapy (DPT) & 90 \\
Speech-Language Pathology (MS) & 49 \\
\hline
\end{tabular}

Faculty Input. Faculty have emphasized the importance of the experience and worked diligently with their schools and universities to incorporate the program into their curricula. As a result, at the medical school all 4th year medical students are required to participate in one of the nine rotations offered each year (each rotation is alike). At the university, all nurse practitioner, clinical nurse specialist, speech and language pathology, and physical therapy students are required to participate. Because of the program's reputation and success, the athletic training and dental hygiene programs are now requiring all their students to participate. Additionally, two other schools and universities in the state are now involved, adding pharmacy and social work students 
to the interprofessional student teams. Faculty from all disciplines participate in each rotation and actively facilitates the standardized patient experiences and website development.

Student Outcomes. To assess the success of the rotation, students complete the following: (1) the Interdisciplinary Education Perception Scale (IEPS), (2) a questionnaire regarding Telehealth Etiquette both pre- and post rotation measures, and (3) an exit survey that evaluates the immersion experience. The pre-post tools use a Likert scale from $1=$ Strongly Agree to $5=$ Strongly Disagree.

During the last 6 months of the project, a focus has been on assessing pre- and post outcomes. Thus, to date, the number of pre-post surveys identified as pairs are 79 (13.3\%). The results show significant improvement of students' perceptions of interdisciplinary education as well as improvement in the skills for use of telehealth with the largest effect size for the Telehealth Etiquette. (See Table 7).

Table 7: Pre-post results from Survey Tools Non-parametric ( $\mathrm{N}=79$ Pairs).

\begin{tabular}{lllll}
\hline Measurement Tool & Pre M (SD) & Post M (SD) & p-value & $\begin{array}{l}\text { Cohen's d (effect } \\
\text { size) }\end{array}$ \\
\hline IPES & $1.9(0.30)$ & $1.8(0.30)$ & 0.008 & 0.33 \\
Telehealth Etiquette & $1.7(0.39)$ & $1.4(0.39)$ & 0.0001 & 0.75 \\
\hline
\end{tabular}

Note: Interdisciplinary Education Perception Scale = IPES, M = Mean, SD = Standard deviation.

Exit surveys of 385 (65\%) students following phase 2 with the standardized patients and telehealth indicate that the experience refines their abilities to perform as an interprofessional team related to: 1) eliciting a history from the patient $(\mathrm{n}=325,84 \%), 2)$ communicating verbally $(\mathrm{n}=351,91 \%)$ and non-verbally $(\mathrm{n}=330,86 \%), 3)$ providing patient education $(n=330,86 \%)$, and 4$)$ developing a management plan $(n=385,100 \%)$. Sixty-five percent of the students feel that the cases are at their level of knowledge and $35 \%$ feel they are complicated. The students rate the qualities of the standardized patients as "somewhat excellent" to "excellent" related to realism $(89 \%)$, quality of feedback $(89 \%)$, ability to demonstrate clinical signs ( $82 \%)$, and professionalism $(93 \%)$. All the students feel that the experience improves their understanding of telehealth with more than $68 \%$ stating they are "moderately" to "significantly improved". The students also feel that the experience improves their interprofessional and team skills with $68 \%$ stating that their skills are "moderately" to "significantly improved".

Through anecdotal comments regarding interprofessional collaboration, students emphasized: (1) the quality of the teamwork experience such as, "this was the best team experience I have participated in" and they appreciated the "realism, variety, and the opportunity to work as a team", (2) the importance of interprofessional collaboration such as, "interprofessionalism is key to meeting all of the patient's needs", (3) the importance of self-awareness, such as the simulations helped with, "team collaboration, self-awareness" and it "helped me assess my strengths and weaknesses", and (4) the impact of the session such as, "It was very helpful to be able to go through a case as an interprofessional team and learn how to act as one unit" and "Overall experience was great; nice to integrate professions, I think it will help healthcare as a whole. Great to work with strangers and come together for an ultimate goal".

Comments related to the telehealth experience indicated that the students benefitted from: (1) "Techniques on how to combine different professions to solve the case via teleconference", (2) "Using the new equipment, attempting to collaborate, and regrouping", and (3) "working with actual equipment".

Recommendations for the programs included having the experience earlier in their education, having more professions involved, and having more time in the experience. Overall the experience is well-received.

\section{Conclusions and implications}

Students come away from the interprofessional experience with a better understanding of team based care. They are able to discuss the difference between care in silos versus interprofessional collaborative care. Despite many of the students having had exposure to clinical practice, many have not experienced telehealth or interprofessional teams in their clinical settings. Faculty and students alike are amazed by how quickly student groups move through the stages of team development and begin working towards a final project. Not only are professional barriers removed during this experience, but so are the structural barriers of disparate curricula/schedules across health provider training programs and universities.

During the initial care planning presentations, most student groups address the patient's condition and needs from each professionals training and competencies rather than the patient's needs. It is not until the groups place the patient's needs at the center of the team does the real interprofessional work begin. Faculty 
realized early in the development of this program that the student groups default to the comfort of their professional roles and responsibilities; through faculty guidance student groups shift their focus to the patient rather than what each profession has to offer. While the online work provides a necessary introduction to interprofessional collaborative practice and telehealth, the didactic content is not enough. It is during the day-long faceto-face seminar/immersion that real interprofessional communication, understanding, teamwork, and sharing of values begins. Student groups evolve into a respectful interprofessional team over the 8-hour day.

Despite the fact that the students' real work as a team begins in a virtual world, most students are apprehensive about the telehealth equipment and telehealth visit. Many have little to no exposure with telehealth. Some students express concern prior to the telehealth encounter that the computer screen will limit ability to compassionately connect with a patient. Most also initially wonder how they could incorporate telehealth into an interprofessional visit with patients. It is not until the groups successfully complete a telehealth visit with the standardized patient that they realize this type of visit, while different, is not difficult. Feedback from the standardized patients and faculty is a critical step in this process. The standardized patients are trained in providing objective feedback. It is through this feedback that students improve their assessment skills, telehealth etiquette, and communication skills for telehealth encounters.

The deliverable project that the student groups complete as a website or mobile app serves several purposes. First, students are able to create high level project within one-week despite their competing busy schedules and physical distance from one another. The projects are created to represent each of the professions. Second, it is a regular occurrence for students to state that creating the website is the "Best team experience they have ever had." Students learn to not only utilize technology as a tool to bridge the gap of physical distance and logistical challenges to meeting, but learn how to truly function as an interprofessional team. The websites tend to provide content that was inclusive of all professions represented, and many are of publishable quality based on interprofessional faculty team assessment.

The teaching model presented in this paper, based on Kolb's theory of experiential learning (Kolb, 2014), represents a proven methodology for moving students from concrete learning to active experimentation in as little as 2-weeks. This type of immersion prepares students for both interprofessional care and the use of telehealth. Upon graduation, students from all represented professions will have had an opportunity to successfully work on an interprofessional team. They will not only know what interprofessional teams are capable of managing in terms of complex patients, but will expect this type of team based care and potentially move forward as champions of truly interprofessional collaborative care.

\section{Lessons learned and future direction}

The faculty learned many lessons over the two and one half-years of this program's implementation. First and foremost, the faculty found that to deliver such a successful program that is so well received by both students and faculty, all professions represented must be involved in the development and implementation of the interprofessional program. All too often, faculty believe they truly understand another profession and can teach about others' roles in healthcare, however; we learned that we knew less than we ever imagined regarding the role of the professions on the team. For the program to be accepted, students need to have a faculty member that represents their profession during phase 2. This allows the students to receive input from experts in each profession represented. In addition, it provides students with confidence as they attempt to represent their own profession.

It is harder to teach interprofessional collaboration than anticipated. Many of the typical approaches to interprofessional education did not truly work; traditionally structured didactic classes often allow students to remain in their professional silos. Thus, experiential learning was used to break down the professional divides. This experiential learning is reinforced by discussing behavioral tendencies, ethics, and the human factors (etiquette) that impact how an individual performs on a team regardless of their profession. By having the final phase focus on the development of a product such as a website, the students are forced to work together and overcome barriers that could interfere with interprofessional collaboration.

The fact that this experience occurs over a two-week period and only has one on-campus day increases the willingness of each profession to become involved and decreases the burnout of faculty. The students can stay focused on the program by choosing the rotation that best fit their own schedule. This allows for smaller groups - groups with 5-6 students from different professions were ideal.

Several changes were made to the two-week rotation to improve the impact and flow. Changes to the standardized patient encounters consisted of: (1) having students interact with the standardized patients through a face-to-face visit initially followed by a telehealth visit -originally both encounters occurred via telehealth which overshadowed the IPE learning and (2) instructing students to focus on the role of collaboration during 
the standardized patient sessions as opposed to medical management - students tended to get stuck on the medical issues, such as the medical students developing a plan for treating the infected limb in the veteran case and forgetting that other professions should be involved in the care. Quizzes initially used to assess the impact of the modules were not effective in accomplishing the goals of collaboration and telehealth proficiency. Thus, the quizzes were replaced by having the students develop a plan of care based on a patient scenario.

To continue the program with the HRSA funding expiring, new methods of funding have become necessary. Specific strategies have included incorporating a lab fee paid by students that covers the standardized patient program. Faculty participation in the program is being recognized as part of their teaching responsibilities. Refinement will continue in order to address new trends, technology, and issues in healthcare. This experience has had a positive impact on the understanding of interprofessional education and the use of telehealth for students from various health professions. It has been an effective and innovative means of providing interprofessional experiences for students in different learning environments with different schedules. This model is used as a response to the current mandates for increased interprofessional education currently required by professional organizations. The incorporation of telehealth prepares students for the future in healthcare as well as a means for overcoming the barriers associated with distance that too often compromise interprofessional collaboration.

\section{References}

American Academy of Ambulatory Care Nursing (2011) Telehealth nursing practice scope \& standards of practice. Retrieved from https://www.aaacn.org/tnp-scope-standards-practice

American Medical Association (2016). AMA encourages training in telemedicine for medical students and residents. Retrieved from http://www.ama-assn.org/ama/pub/news/news/2016/2016-06-15-telemedicine-training-students-residents.page

American Physical Therapy Association. (2017). Telehealth. Retrieved from http://www.apta.org/Telehealth/

Ellison, A. (2016). The rural hospital closure crisis: 15 key findings and trends. Becker's Hospital Review. Retrieved from http://www.beckershospitalreview.com/finance/the-rural-hospital-closure-crisis-15-key-findings-and-trends.html

Ferris, N. (2006). IT makes medicine a team sport, expert says. Healthcare IT News. Retrieved from: http://www.healthcareitnews.com/news/itmakes-medicine-team-sport-expert-says-ovb

Haney, T., Kott, K., \& Fowler, C. (2015). Telehealth etiquette in home healthcare: The key to a successful visit. Home Healthcare Now, 33(5), 254-259. doi:10.1097/NHH.0000000000000228

Healthy People 2020 (2016). Older adults. Retrieved from https://www.healthypeople.gov/2020/topics-objectives/topic/older-adults Institute of Medicine. (2001). Crossing the quality chasm: A new health system for the 21st century. Washington, D.C.: National Academy Press. Interprofessional Education Collaborative (2016). Interprofessional education collaborative releases revised set of core competencies. Retrieved from https://www.ipecollaborative.org/uploads/IPEC-2016-Core-Comps-Press-Release_final_.pdf

Interprofessional Education Collaborative Expert Panel. (2016). Core competencies for interprofessional collaborative practice: Report of an expert panel. Washington, D.C.: Interprofessional Education Collaborative. Retrieved from https://nebula.wsimg.com/2f68a39520b03336b41038c370497473?AccessKeyld=DC06780E69ED19E2B3A5\&disposition=o\&alloworigin=1.

Kolb, D. (2014). Experiential learning: Experience as the source of learning and development (2nd Edn ed.). Indianapolis, Indiana: Pearson FT Press.

National Council of State Board of Nursing (2014). The NCSBN position paper on telehealth nursing practice. Retrieved from htpps://www.ncsbn.org/3847.htm

Nester, ]. (2016). The importance of interprofessional practice and education in the era of accountable care. North Carolina Medical Journal, 77(2), 128-132. doi:10.18043/ncm.77.2.128

Poore, J. A., Cullen, D. L., \& Schaar, G. L. (2014). Simulation-based interprofessional education guided by Kolb's experiential learning theory. Clinical Simulation in Nursing, 10(5), e241-e247. doi:10.1016/j.ecns.2014.01.004

Reeves, S., Perrier, L., Goldman, J., Reeth, D., \& Zwarentsten, M. (2013). Interprofessional education: Effects of professional practice and healthcare outcomes (update). Cochrane Database of Systematic Reviews, 28(3), 1-49. doi:10.1002/14651858.CDoo2213.pub3

Rojas-Burke, J. (2014). What happens when hospitals abandon inner cities? Retrieved from: http://healthjournalism.org/blog/2014/07/whathappens-when-hospitals-abandon-inner-cities/

Rural Health Information Hub (2017) Rural Aging. Retrieved from: https://www.ruralhealthinfo.org/topics/aging

San Martin-Rodriguez, L., Beaulieu, M. D., D’Amour, D., \& Ferrada-Videla, M. (2005). The determinants of successful collaboration: A review of theoretical and empirical studies. Journal of Interprofessional Care, 1, 132-147. doi:10.1080/13561820500082677

U.S Covernment Publishing Office (GPO) (2010). Public Law-111-148 The patient protection and Affordable Care Act. Retrieved from https://www.gpo.gov/fdsys/pkg/PLAW-111publ148/content-detail.html

World Health Organization (2010). Framework for action on interprofessional education $\&$ collaborative practice. Retrieved from http://apps.who.int/iris/bitstream/10665/70185/1/WHO_HRH_HPN_10.3_eng.pdf?ua=1

Zorek, J., \& Raehl, C. (2013). Interprofessional education accreditation standards in the USA: A comparative analysis. Journal of Interprofessional Care, 27(2), 123-130. doi:10.3109/13561820.2012.718295 